\title{
How Norms In Technology Ought To Be Interpreted
}

\author{
Krist Vaesen \\ Technical University of Eindhoven \\ Philosophy and Ethics of Technology
}

\begin{abstract}
This paper defends the claim that there are - at least two kinds of normativity in technological practice. The first concerns what engineers ought to do and the second concerns normative statements about artifacts. The claim is controversial, since the standard approach to normativity, namely normative realism, actually denies artifacts any kind of normativity; according to the normative realist, normativity applies exclusively to human agents. In other words, normative realists hold that only "human agent normativity" is a genuine form of normativity.

I will argue that normative realism is mistaken on this point. I will mainly draw on material of Daniel Dennett and Philip Pettit to show that it makes sense to talk about artifactual normativity. We claim that this approach can also make sense of human agent normativity — or more specifically "engineer normativity". Moreover, it avoids some of the problems formulated by opponents of normative realism. Thus I will develop a strategy which: (i) makes sense of artifactual normativity; and (ii) makes sense of "human agent normativity", specifically "engineer normativity".
\end{abstract}

KEYWORDS: Normative Realism - Response-dependence Normativity — Technology — Interpretation

\section{Introduction}

In a now classic paper Hector-Neri Castañeda developed a theory of normativity consisting of two main categories: the category of ought to do and the category of ought to be ${ }^{1}$. Some authors accepted this distinction, while offering more elegant formulations. They would, for example, rather

\footnotetext{
${ }^{1}$ Castañeda, 1970.
} 
Technè 10:1 Fall $2006 \quad$ Vaesen, How Technology Ought To Be Interpreted.../118 talk about deontic normativity (ought to do) and evaluative normativity (ought to be). Others have doubted such a distinction can be made at all. Roughly stated, they claim that the evaluative can be reduced to the deontic. For instance, to say an act was right, means nothing more than that the agent has done what he ought to have done ${ }^{2}$.

At first sight, it seems the philosophy of technology could benefit from Castañeda's distinction, since it seems apt to define two forms of normativity in technology. The category of ought to do would in that case cover statements about what the engineer ought to do - how he ought to design his artifacts, for instance. The category of ought to be, on the other hand, would relate to how artifacts ought to be - e.g. the dimension of a piece of A4 paper ought to be $210 \mathrm{~mm} \times 297 \mathrm{~mm}$.

To some extent I will defend and make more explicit this line of argument in the course of the present paper. However, I will formulate it differently. From now on, I will not speak about "ought to do" and "ought to be", but about "human agent normativity" and "artifactual normativity". On this account artifactual normativity not only comprises ought to be statements, but some ought to do statements as well, such as: this artifact is a watch, so it ought to perform its intended function, namely it ought to keep the time.

The aim of this paper, then, is to answer the question: can we make sense of this so-called artifactual normativity? I will contend that, indeed, we can.

I will proceed as follows. First, I will say something about normative realism, which is arguably the standard approach to normativity. I will argue that normative realists cannot account for artifactual normativity. They may argue that this is no problem at all, since there is no such thing as artifactual normativity. I will argue that this artifactual normativity is, on the contrary, essential for making sense of engineering norms.

Indeed, I will go a step further. I will argue that normative realism is a poor candidate to account for human agent normativity as well. To do that, I will invoke two points of criticism, which I call the problem of autonomy and the problem of intentionality.

In sections 4 and 5, I will develop an alternative that makes sense of artifactual normativity and, at the same time, makes better sense of human agent normativity. It will be interpretative and dispositional in nature.

\footnotetext{
${ }^{2}$ Dancy, personal communication.
} 
In section 6, I will programmatically deal with some ontological issues and suggest that my account is not anti-realist nor relativist. Finally, section 7 ends with some concluding remarks.

\section{What Normative Realists Ought To Reconsider: Part I}

Clearly, I have some doubts about what normative realism as a theory might achieve, but let us begin with a short summary of the theory.

Normative realists maintain that normativity can be explained - if it can be explained at all - in terms of reasons. More importantly, normative realists think those reasons are facts, facts which, more or less independently of our human make-up, provide reasons in virtue of their own nature ${ }^{3}$. So, if Jesse has a reason not to play with guns, the normative realist would say, it is because what playing with guns consists in, and not because of Jesse's psychological make-up, desires, and the like. Playing with guns is objectively wrong and this fact gives people a good reason not to play with guns.

In the 1970's, Joseph Raz first explored normativity in terms of reasons. He remains loyal to the basic idea: 'The normativity of all that is normative consists in the way it is, or provides, or is otherwise related to reasons. ${ }^{4}$

Raz characterizes a norm as follows ${ }^{5}$ : A norm is a fact which operates as an exclusionary reason. This means that a norm contains not only a first-order reason, stating what one ought to do, but a second-order reason as well, namely an exclusionary one: it excludes acting for another (competing) reason. Consider for instance the imperative "Obey your superior". According to Raz, it derives its normativity from the fact that it provides a reason to obey your superior and that it implies furthermore that you ought not to act for any other reason; irrespective of other considerations, you ought to obey your superior.

Following von Wright, Raz discerns four elements in any norm ${ }^{6}$ : (i) the deontic operator (the so-called ought); (ii) the norm subjects, namely the persons required to behave in a certain way; (iii) the norm act, namely the action which is required of them; and (iv) the conditions of application,

\footnotetext{
${ }^{3}$ Here I follow a formulation of Lillehammer (2002 and 2003).

${ }^{4}$ Raz, 1999, p. 67.

${ }^{5} \mathrm{Raz}, 1975$ \& 1990

${ }^{6}$ Ibidem, p. 50.
} 
Technè 10:1 Fall 2006 Vaesen, How Technology Ought To Be Interpreted.../120 namely the circumstances in which they are required to perform the norm action.

For my purpose, element (ii) is crucial: according to Raz norms only apply to human agents and their actions. Human beings might have reasons to do such-and-such, objects don't. Corollary: unless Raz agrees to take a Dennettian interpretative stance towards artifacts - and I am confident that he, as a realist, would not — artifactual normativity does not fit into his normative realist account. I will later argue that this is a deficiency, but let us first show that Raz is not alone in this conclusion. We will examine a second normative realist, Jonathan Dancy, and show that he is committed to the same conclusion - artifactual normativity is unexplainable for the normative realist. Along the way, I will sketch some arguments to be used in later sections.

Dancy's particularism reacts to the fact that authors, such as Raz, restrict normativity to so-called perfect reasons, i.e. reasons which cannot be overruled by any other consideration ${ }^{7}$. Dancy claims that such perfect reasons don't exist. He defends the thesis that all reasons are pro tanto ${ }^{8}$. Consider the norm "Obey your superior". In some cases, it indeed excludes disobedience, in other cases, the norm will be weighed against other reasons; your superior might be drunk or may ask you to do something highly despicable. A pro tanto reason, then, is a reason which is, all things considered, the best reason to act upon.

If we agree with the particularist, we can not understand the normative merely in terms of reasons which exclude other options - like Joseph Raz does. Dancy's account attempts to reconcile normative realism and particularism by explaining normativity in terms of "favouring". He holds that normative reasons are reasons which favour certain paths of action and, importantly, that favouring comes in different degrees. Some facts are more decisive than others; some speak modestly in favour of doing $\mathrm{X}$, others cry out loud, so to speak. Confronted with conflicting reasons, agents weigh them and generally select the most favouring reason for action. All things considered, it is the best reason at hand.

\footnotetext{
${ }^{7}$ More accurately, Raz allows for non-perfect reasons as well. He calls them non-mandatory reasons. This means they are mildly exclusionary; they permit you to refrain from other (competing) reasons. It is however hard to see how such non-mandatory reasons differ from ordinary reasons. 8 Dancy, 2004.
} 
Technè 10:1 Fall $2006 \quad$ Vaesen, How Technology Ought To Be Interpreted.../121 Thus, like Raz, Dancy reduces normativity to reasons for human action 9 . Maintaining that a knife ought to be sharp, for example, is a non-normative claim, unless it favours further action, such as giving the engineer a reason to produce sharp knifes.

I hope it's clear that both in Raz's and Dancy's account there is no room for artifactual normativity. But why should this be a problem?

First, it is widely agreed that normativity is related to certain ought statements. The exact nature of this relationship and whether oughts can be analyzed at a more primitive level remain open issues - or, better, topics for philosophical dispute. Saying, as normative realists do, that normativity is related to reasons is one thing; defining, for instance, when mere reasons turn into normative reasons - presumably the crux of the question: what is normativity? — is another. And so far — as Jonathan Dancy concedes ${ }^{10}$ nobody has come up with a satisfying answer to this question, except by relying on mere intuitions. Pending settlement of this point, I think it is reasonable to maintain a rather liberal account of normativity and claim that my intuitions are different from those of the normative realist: ought statements about artifacts are normative. Of course, this is too easy a way out, so I will develop two other lines of argument.

First, restricting normativity to human agent normativity seems in conflict with our everyday use of the term "norm". Consider an example taken from the technological sciences: the Dutch Institute for Norms and Normalization. It is, so to speak, a gathering point for norms; norms which not only concern the conduct of engineers producing artifacts, but also the artifacts themselves. For a car to be marketable it ought to function properly and it ought to conform to certain standards - for instance, it ought to comply with certain emission standards, it ought to pass such-and-such crash tests, and the like. Of course, such norms might function as a motivational element in human behavior, for instance, in the behavior of engineers designing the artifacts which ought to be so-and-so. But such norms seem independently relevant in legislation and in cases where a user evaluates a certain artifact. In such cases, the primary focus of the evaluator is the artifact, not the behavior of its designer. The most natural way to describe norms, I suggest, is to think of them as idealizations of how things ought to be done or ought to be. For example: in order for a human agent to meet the norms of rationality, he ought to act so-and-so; in order for an artifact to meet the norms of

\footnotetext{
${ }^{9}$ Dancy, personal communication.

${ }_{10}$ Dancy, personal communication.
} 
Technè 10:1 Fall $2006 \quad$ Vaesen, How Technology Ought To Be Interpreted.../122 optimality, it ought to be so-and-so, or ought to perform this-and-that. On this account, then, the difference between agent and artifactual normativity would be related to what the norms are about: in agent normativity, norms are about human beings and their actions, artifactual normativity on the other hand concerns artifacts.

Of course, the normative realist could grant that in natural language we do indeed use normative notions when talking about artifacts; but, as a philosopher, (s)he has taken up the job to tidy up the sloppiness of natural language. (S)he might do this by following at least two other lines of argument. The first is to claim that so-called artifactual norms are nonnormative, since they merely refer to expectations. Second, the normative realist could hold that these so-called norms are to a certain extent normative, but in a derivative sense: their normativity ultimately can be reduced to norms about actions, say, the designer ought to have taken. By giving three examples, I will show the problems of both strategies, and thus put the burden of proof on those who deny artifacts any kind of normativity.

First, if artifactual norms were expressions of mere expectations, it would be hard to understand cases in which expectations yield evaluative judgments. Suppose I drop a pen. My expectation is that it will fall. This is sometimes expressed as, "when I drop it, it ought to fall," but clearly the ought here is non-normative. It does not support evaluative judgments: if the pen somehow fails to fall, I wouldn't judge it a bad pen. Nor will I call the manufacturer to tell him the pen was poorly designed. On the other hand, if I use it to write down something and see that no ink is released, my claim 'The pen ought to release ink', is not only about what I expect the pen to do, but also relates to what it (normatively) ought to do, given its intended function. Only when I have such intended function in mind, I am in a position to judge the pen to be 'good' or 'bad', a judgment I wouldn't make about the pen disobeying the laws of gravity.

The example illustrates that artifactual oughts may have two sides: an evaluative one and one casting expectations. A second example, however, can show that some of those oughts are merely evaluative, and even stronger, that they are at odds with our expectations. Suppose you find your car, lights still on. They still glow, but only dimly; presumably your battery has run low. In this case, your judgment 'my car ought to start', surely doesn't reflect what you expect: you reasonably believe your battery has run low, so you predict that your car will not start. Again, your judgment is framing what the car ought to do, in order for it to fulfill its functional role. You may take yourself responsible for the car's malfunctioning, or shift responsibility to its producer: the latter has done a poor job, (s)he should have built in an 

automatic light extinguisher.

A final example should make clear why evaluative judgments about artifacts not always can be reduced to agent normativity. Indeed, if your new car is malfunctioning, you can hold its producer responsible: (s)he ought to have designed it so that it, say, does not explode when you turn the ignition on. But what if your car is malfunctioning just because it's an old one? Because it is a car, there are certain functions it ought to perform: for instance, it ought to start when I turn the key. Since it doesn't, it is a malfunctioning car: it's a poor means of transportation. Nevertheless, it is hard to see how we could translate this evaluative judgment in terms of human agent normativity. Cars age and their components get worn-out; no designer has ever come up with an immortal car, so holding the car manufacturer responsible seems a bit forced. (S)he has done what (s)he had to do, at least within the boundaries of the current state of the art.

Now, these arguments might not to be decisive. I just have shown the problems one can encounter, when one denies artifacts any kind of normativity. Perhaps there are other arguments that deny artifactual normativity and avoid these issues. If so, I cannot find them. In the meantime, I think it is reasonable to take a modest, pragmatic position: our concept of artifactual norms has instrumental value, since it allows us to make better sense of engineering practice and engineering language. Therefore, the question whether they are genuinely normative is of minor importance and can be postponed until a definitive and complete account of normativity settles the issue.

\section{What Normative Realists Ought to Reconsider: Part II}

Normative realism doesn't make sense of artifactual normativity, I claimed. But, is its explanation of agent normativity satisfactory? I will contend it isn't. I will formulate two general points of critique. They may be not decisive, but will justify at least why I will develop an alternative (sections 4$6)$.

First, recall that normative realism adheres to the thesis that agents have good reasons to act in some ways rather than others in virtue of the existence of an independent normative reality, the latter consisting of reason giving options ${ }^{11}$. It claims that options themselves provide sufficient reasons merely in virtue of their own nature, irrespective of human make-up, desires,

\footnotetext{
${ }^{11}$ See Lillehammer 2002 and 2003.
} 
Technè 10:1 Fall $2006 \quad$ Vaesen, How Technology Ought To Be Interpreted.../124 rationality, and the like. In other words, the normative realist holds to a response-independent normative reality. To understand this view even better, let me contrast it with an account of response-dependence.

Response-dependent theorists hold to what we might call the rational intelligibility condition. This condition stipulates that options provide normative reasons only in virtue of being responded to by rational agents. Agents have normative reasons to pursue desires only on the condition that these desires would be endorsed in rationally favourable circumstances. Where the normative realist maintains that options provide normative reasons in virtue of their intrinsic nature - say, their intrinsic goodness - the response-dependency theorist will claim they do so in virtue of their external relations to the responses of agents to those options. Thus, while the goodness of an option is an intrinsic property for the normative realist, the response-dependent theorist defines it relative to the rationality of the agent confronted with it. In Michael Smith's words, an option is a good option in as far as a fully rational agent would desire it ${ }^{12}$.

I will return to response-dependency in section 4. For now, I hope to have illustrated what it means to say that the normative realist holds to a responseindependent normative reality.

Now, one problem of normative realism I will call the autonomy problem. It is related to the following ${ }^{13}$. Suppose normative realists are right and that normative reasons indeed are to guide human action. Then, on a purely response-independent account it would be hard to explain the fact that finite human beings are able to recognize them and to respond to them. As Lillehammer says ${ }^{14}$ :

If ends provide reasons in virtue of their nature, what is to stop this nature from being such as to outrun the best possible efforts of finite agents to grasp them as reason-giving in rational deliberation?

If humans are in no position to recognize reasons, then reasons lose their normative and practical function. It would be impossible for them to guide us, to improve, correct and evaluate our actions. In a sense, they are too autonomous to perform their supposed normative tasks.

\footnotetext{
${ }^{12}$ Smith, 2002, p. 329.

${ }^{13}$ Here I rephrase an argument of Lillehammer (2002, p.50).

${ }^{14}$ Lillehammer, 2003, p.4.
} 
Technè 10:1 Fall $2006 \quad$ Vaesen, How Technology Ought To Be Interpreted.../125

So what the rational intelligibility condition urges is that the extension of normative reasons be constrained by facts within the grasp of finite agents who reason soundly. Thus, the normative realist should make plausible that normativity involves at least some constraint(s) on the make-up of agents. Like Christine Korsgaard has argued: any realist account divorcing the existence of reasons from the exercise of a capacity for practical rationality fails to answer the normative question ${ }^{15}$.

Lillehammer, however, doubts that the normative realist can do so ${ }^{16}$. Rather, he alleges that intermediate positions which claim to reconcile normative realism with a form of response-dependency are untenable. It is beyond the scope of this paper to scrutinize his arguments. Besides, I think normative realism faces yet another problem. It is what I call the problem of intentionality, and I think it speaks even more in favour of abandoning normative realism.

Defenders of normative realism often use phrasings such as: options or facts are normative reasons in as far they "exclude" 17 "favour" 18, "prescribe", and "contribute to" certain paths of action, insofar as they "speak" to us, insofar as they "tell" us what to do. I find these formulations pretty odd. If one says that a fact favours a certain way of going on, how does this favouring work? By what kind of magic does the fact that "playing with guns is wrong" speaks to us?

The point I want to make is the following: normative realists take a kind of Dennettian intentional stance towards facts and reasons, because they have to. If the clue to normativity is to be found in an independent normative reality, the latter actually has to do something; facts are to be interpreted as intentional agents who "speak" or "favour" or "prescribe." 19

To be clear, I have no objections to intentional stances as such although I doubt that normative realists share my instrumentalist tendencies. In any case, I think that they should be more explicit about what they exactly hope

\footnotetext{
${ }^{15}$ See Korsgaard, 1995, p. 14ff.

${ }^{16}$ see Lillehammer, 2003.

${ }^{17}$ See my explanation of Raz's account, section 2.

${ }^{18}$ See my explanation of Dancy's account, section 2.

${ }^{19}$ And not only that, they should do it in such a way that finite human beings are able to receive the message. In speaking, the fact that "playing with guns is wrong" should keep, so to say, in the back of its mind, that its message should be recognizable to human beings. Maybe it's my lack of imagination, but I do not see how facts (be it stone-facts or so-called objective normative facts) can do all that.
} 
Technè 10:1 Fall 2006 Vaesen, How Technology Ought To Be Interpreted.../126 to explain, when they intentionalize facts and reasons. Perhaps they are merely talking "metaphorically", but this metaphor should be explained since it has wide-ranging repercussions. For one thing, it puts their so-called realism in jeopardy and with it the existence of an independent normative reality, unless the latter consists of concepts instead of (normative) facts. Second, it is unclear what lies underneath their metaphorical talk. Consider Dancy's favouring relation: the normative fact that "playing with guns is dangerous" favours Jesse's not playing with guns. Is this favouring a causal relation? Dancy says no ${ }^{20}$. As a non-naturalist, he believes that the normative does not supervene on the descriptive; he thinks there is a normative realm, which does not necessarily correspond to a descriptive counterpart. Favouring is the basic normative relation and doesn't need further explanation; it just occurs. Why and how? We just don't know. (Nevertheless, I want to know.)

Both remarks concerning the problem of autonomy and intentionality lead me to the following conclusion: Normative realism is at best a theory to make sense of and interpret human action. It might indeed have some instrumental value and the concepts it offers - such as reasons, prescriptions, and the like - probably are used in our common-sense vocabulary and our folk morality. Nevertheless, I think it would be better to develop an interpretative strategy which has at least some underpinning in our natural world. It ought to be a theory which avoids what Blackburn calls a Platonic mystery, i.e., a theory which does not rely on '[normative] facts which bear only a strange relationship to the natural order, and whose own credentials and authority remain shrouded in obscurity ${ }^{21}$, To such theory we turn now.

\section{Oughts in Rational Explanations}

Thus far I have told a negative story. To sum up, an alternative should meet three criteria:

(A.i) it should explain artifactual normativity;

(A.ii) it should avoid the autonomy problem by taking into account human dispositions;

and

(A.iii) if interpretative, intentional terms should somehow be backed up by a causal story.

\footnotetext{
${ }^{20}$ personal communication.

${ }^{21}$ Blackburn, 1998, p. 55.
} 
Technè 10:1 Fall $2006 \quad$ Vaesen, How Technology Ought To Be Interpreted.../127 I think a form of interpretative dispositionalism is a fair candidate. I will introduce the basic notions in this section, and apply them to technology in section 5 .

In general, on a dispositional or response-dependent account of an entity, say a value, the nature and existence of that entity is constituted by the responses of agents to the world in some non-trivially defined set of favourable circumstances ${ }^{22}$. Consider again Michael Smith's dispositional theory of value: an option is a good option insofar as a fully rational agent would desire it. This means the goodness of an option is not an intrinsic property, but is defined by a human response [viz. a desire] in a set of favourable circumstances [viz. under the condition the agent is fully rational].

Now, if we want to make sense of an agent's behaviour, we can similarly refer to his distinctive psychological responses: roughly, by reference to the psychological states which reflect the information he has recorded and the inclination that moves him, in short, by reference to his beliefs and desires. Of course, such explanations in terms of mental states are not genuinely causal. Nevertheless, I take it to be uncontroversial that they are in some way related to a causal story, a story probably in neurophysiological terms - a form of causality I claimed to be lacking in normative realist accounts. In fact, we might say we have two kinds of explanations: a neurophysiological one, dwelling in the order of causality, and one in terms of the mental, dwelling in the order of rationality ${ }^{23}$. Thus, mental states are characterized by their place in a rational structure. And as Simon Blackburn says:

[...] "rational" here means normative: it tells us how it would make sense for a person to factor a belief or desire into a pre-existent matrix of mental states. [...] It is a matter of 'rationalizing' the subjects, hypothesizing that they believe what they ought to believe, and desire what they ought to desire, or at least what it makes sense for them to desire $^{24}$.

This means we interpret human beings as creatures with beliefs, desires, and other states of mind who behave in ways that makes sense, given those states of mind. It must be clear that this interpretative strategy comes close to a form of Dennettian interpretationism. To be more specific, when

\footnotetext{
${ }^{22}$ See Lillehammer, 2003, p. 5.

${ }^{23}$ Both orders are close to what Daniel Dennett calls the physical and the intentional. See Dennett, 1987.

${ }^{24}$ Blackburn, 1998, p. 53-54, italics added.
} 

Stance (IS):

Here is how it works: first you decide to treat the object whose behavior is to be predicted as a rational agent [i.e. you put a rationality assumption in place, K.V.]; then you figure out what beliefs that agent ought to have, given its place in the world and its purposes. Then you figure out what desires it ought to have, on the same considerations, and finally you predict that this rational agent will act to further its goals in the light of its beliefs. A little practical reasoning from the chosen set of beliefs and desires will in many — but not all — instances yield a decision about what the agent ought to do. ${ }^{25}$

Moreover, like Blackburn, Dennett discerns between causal and rational explanations. First, causal explanations are the outcome of taking the Physical Stance (PS). PS is an explanatory strategy which appeals to the physics of the explanandum - a particle, an object, an organism. Rational explanations, on the other hand, are the product of an IS. The latter is normative, since you explain, under the assumption of rationality, what a certain intentional system ought to do - as suggested by Dennett's quote above. Or, following Pettit ${ }^{26}$, we can characterize it by a hypothetical imperative:

if an agent is to count as a rational being, given his beliefs and desires, he ought to act so-and-so.

First, note that this formulation is close to my suggestion (section 2) that norms are idealizations, putting comparative constraints on how things ought to be done or how they ought to be. Second, I think we already have met constraints (A.ii) and (A.iii). Recall that (A.ii) stated that we are in need of a theory which takes human dispositions into account, in order to avoid the socalled autonomy problem. The goodness of an action - the thing an agent ought to do - is, on our account, dependent on responses [viz. beliefs, desires] in a set of favourable circumstance [viz. under the condition is the agent is rational]. Moreover, (A.iii) is met as well. Our strategy is interpretative and the entities we pose have a causal counterpart. To understand this, we can refer again to Dennett. His PS and IS are not entirely unrelated. Intentional systems to be explained by taking an IS, are just a subset of all materially existing entities. And again, beliefs and desires as

\footnotetext{
${ }^{25}$ See Dennett, 1987 , p. 17 , italics added.

${ }^{26}$ See Pettit, 2002, p. 283.
} 
Technè 10:1 Fall $2006 \quad$ Vaesen, How Technology Ought To Be Interpreted.../129 used in IS, can to a certain extent be explained in physical terms, that is, by taken a PS towards them. Of course, I keep the PS/IS relationship rather vague, since a thorough analysis is, unfortunately, beyond the scope of this paper.

With this in mind, there remain two things to be done. First we need to make sense of (A.i) and we need to apply (A.i)-(A.iii) to technology. This is the subject of next section.

\section{Norms in Technology: Explaining Human Agent and Artifactual Oughts}

Let's start with human agent normativity. The hypothetical imperative (B) can be rephrased as follows: in explaining the actions of an agent, we put in place an assumption that, absent malfunction and other disturbing factors, the agent satisfies the role of a rational agent: he is more or less rational in its responses to evidence and more or less rational in moving from what he believes and from his values values to what to do ${ }^{27}$. Given an antecedent state, the agent ought to do X, on pain of being irrational; or, if he is to fulfill his role as a rational agent, he ought to respond according to the norms of rationality. With the aforementioned assumption in place, we are in a position to explain what the agent ought to do. Without it we would fail to explain, interpret or understand human behaviour.

Now, to explain the actions an engineer ought to perform, we first have to add that people satisfy the role of rational creatures as a result of natural selection and of cultural influence ${ }^{28}$. What it is for an engineer to be rational presumably differs from, say, scientific rationality, since both forms of rationality have evolved in different cultural niches. For instance, it might be rational for an engineer to act upon false beliefs, say as a heuristic to gain time; if a scientist would do the same, we usually would call him irrational. Rationality is a multi-faceted notion which co-varies with the conditions of its application, and this, in turn, has repercussions on our interpretations. It is reasonable to suppose that, when I interpret the actions of an engineer, I put a different rationality assumption in place, for instance, than when I interpret the actions of a scientist.

An obvious challenge to this approach is that I haven't said anything about what this engineering rationality consists in. I might seem to have shifted the

\footnotetext{
${ }^{27}$ See Cherniak, 1986 and Pettit, 2002.

${ }^{28}$ See Dennett, 1995, p. 506 and Pettit, 2002, p. 185.
} 
Technè 10:1 Fall $2006 \quad$ Vaesen, How Technology Ought To Be Interpreted.../130 normative question to a question of rationality. Nonetheless, I hope to have shed light on these issues. For one thing, I have suggested where to look for an answer and, as important, where not to look: in the realm of normative realism. Second, the purpose of the present paper was to overcome some problems of normative realism; it goes without saying that further research needs to flesh out the rationality assumption I use. In future work, I will offer an account of engineering rationality by altering Dennett's Stance Theory, which consists of three stances: the earlier mentioned PS and IS, and the Design Stance (DS). This last is an interpretative strategy to explain the behavior of designed entities, both biological and artificial ${ }^{29}$. I will introduce projective correlates to these stances. Engineers, I argue, do not interpret actual artifacts (as in DS) or actual users (as in IS), but try to predict the behavior of artifacts which do not exist yet and of possible users.

The remainder of this section, now, will concentrate on one problem I promised to solve: how to understand artifactual normativity. As for agent normativity, I will do this by means of interpretative strategies.

Let's start with an example ${ }^{30}$. Suppose we have designed a computer to add numbers presented to it and to display the sum: we have designed it to function as an adding device. The computer is a designed entity, so Dennett's DS applies. Thus, we ignore the details of the physical constitution of the object, assume that it has been designed with a certain purpose in mind, and explain its behavior accordingly. Instead of working under the assumption of rationality (as in IS) however, we put an optimality assumption ${ }^{31}$ in place: the artifact was designed so that it actually can perform its intended function. So, if our design is successful, whenever we present the computer with a set of numbers, it will respond by giving us their sum.

As in the case of human action, the sort of regularity involved in the computer's responses has the status of a norm. To understand this, we can invoke a hypothetical imperative again (cfr. (B)): if the machine we developed is to count as an adder, for input seven and four, it ought to produce output eleven. Or, under the assumption that the system is an adder, we can say that it ought to output the sum of the inputs, where the ought is a normative ought. In this case the norm refers to the ideal state in which the

\footnotetext{
${ }^{29}$ For Dennett biological objects indeed can be considered as designed entities. Interpreting them means we take a kind of intentional stance towards 'Mother Nature', as he calls the process of natural selection.

${ }^{30}$ The example is taken from Pettit, 2002.

${ }^{31}$ In our example such optimality assumption is in fact an effectiveness assumption. For sake of clarity we however stick to Dennett's original terminology.
} 
Technè 10:1 Fall $2006 \quad$ Vaesen, How Technology Ought To Be Interpreted.../131 artifact functions properly. In light of this optimality standard, we interpret and evaluate its functioning.

Artifactual normativity, however, is not restricted to the artifact's capacity to perform its intended function. Take, for instance, the statement: "a car ought to be safe and clean." We can explain its normativity, again by invoking a hypothetical imperative: for a car to be marketable, it ought to be so-and-so; it ought to be safe, it ought to be clean, it ought to comply to certain technical standards and the like.

To sum up, I hope to have shown with sections 4 and 5, that, contra normative realism, it makes sense to talk about artifactual normativity; moreover, I think my account is better suited than its normative realist counterpart, when it concerns the explanation of "engineer normativity".

Before concluding (section 7), I will take up some ontological issues with respect to my proposal.

\section{Ontology And Objectivity Are Not Endangered Species}

This section sketches briefly my ontological commitments. In particular it concerns two questions: (i) does my approach to normativity refer to anything at all?; and (ii) does it exclude the objectivity of norms?

The answer to the first question is: I hope so, but my account doesn't stand or fall with it. The approach I have defended is in both cases [i.e. human agent and artifactual normativity] explanatory in nature. It offers an interpretative strategy, without much of an ontological commitment — maybe apart from the fact that our explanations almost certainly depend on lower-level, causal explanations. In any case, we are interested primarily in the instrumental value of normative theories to the neglect of realist concerns and we believe that our account helps make sense of engineering normativity. I won't illustrate this contention for the case of "human agent normativity" - I think, for instance, Dennett has sufficiently done so - but focus on artifactual normativity instead.

One benefit of my approach is the following. We can learn that a certain system is designed or selected to fit a certain role and we can determine its normative regularities, without having to know the regularities of its lowerlevel causal structure. Knowing the designer or his purposes, or just a little empirical evidence of the system itself, may convince us that this system, say, is a device meant to add. And with this in mind, we are in a position to predict its behavior, absent malfunctioning. Second, such explanations have 
Technè 10:1 Fall $2006 \quad$ Vaesen, How Technology Ought To Be Interpreted.../132 evaluative value. If a certain system is to count as an adder, it ought to be designed in a way that it gives the correct sum when presented with a set of numbers. If it doesn't fulfill this role, it is a bad adder or a malfunctioning one. Third, noticing some regularities in a system might direct us in finding answers to the causal story or history which has brought them about. We might analyze whether and how these regularities were programmed for. Stated differently, the higher-level interpretation of a system's behavior may be of guidance to study its lower-level counterparts.

Now, turning to the second question, I do think my account holds to a certain objectivity of norms. In the case of human agents we work under rationality assumptions, in the case of artifacts we invoke optimality assumptions. Both "rationality" and "optimality" are crucial to our normative claims, that is, they constrain what we reasonably can expect persons and things to do or to be like. For instance, suppose I interpret a person. What he ought to do is not merely dependent on his individual beliefs and desires, but also on what he as a rational being, given his mental states, is supposed to do. As such, the notion of rationality can be used to define better or worse ways of responding to a certain situation. Not any response will do. Whether this is sufficient to be called "genuine" objectivity, I do not know. At least it is not the objectivity, normative realists are after: a set of platonic norms mysteriously trying to persuade us to do this-and-that.

\section{Conclusion}

To give more structure to the story I have told, I will sum up its main contentions. With this paper I hope to have demonstrated that:

1. Normative realism offers at best an interpretative strategy to understand normativity. On one hand this seems incompatible with its realist ambitions. On the other hand, as an interpretative strategy it falls short in two respects: (i) as presented by Raz and Dancy it fails to account for artifactual normativity; and (ii) it lacks a supporting causal story for human agent normativity.

2. If one is to explain the normativity in technology, one has to embrace a kind of dispositional interpretationism. What an engineer ought to do is explained in terms of his responses [viz. his desires and beliefs] under the assumption that he is rational; he ought to do $\mathrm{X}$, on pain of being irrational. What an artifact ought to do is explained in terms of its responses under the assumption that it purports to fulfill its artifactual role; it ought to perform Y, on pain of failing to be a wellfunctioning artifact of type Z. A similar strategy applies when we 
Technè 10:1 Fall $2006 \quad$ Vaesen, How Technology Ought To Be Interpreted.../133 interpret the non-functional normative constraints on artifacts, for instance when we make claims about how an artifact ought to be like.

3. The challenge to this account is to analyze more thoroughly the rationality assumption in the case of engineering actions. Nevertheless, I briefly argued how we could proceed from here on.

\section{References}

Blackburn, Simon. 1998. Ruling Passions: a Theory of Practical Reasoning. Oxford Clarendon Press.

Castañeda, Hector-Neri. 1970. On the Semantics of the Ought-to-Do. Synthese 21: 449-468.

Cherniak, Christopher. 1986. Minimal Rationality. MIT Press.

Dancy, Jonathan. 2004. Ethics Without Principles. Oxford University Press.

Dennett, Daniel Clement. 1987. The Intentional Stance. MIT Press.

1995. Darwin's Dangerous Idea: Evolution and the Meanings of Life. Simon \& Schuster.

Korsgaard, Christine. 1995. The Sources of Normativity. Cambridge University Press.

Lillehammer, Halvard. 2002. Moral realism, Normative Reasons, and Rational Intelligibility. Erkenntnis 57: 47-69.

. 2003. The Metaphysics of Normative Reasons. in Grundlagen Der Ethik: Normativität und Objektivität, edited by ed. Schaber, P. \& R. Hüntelman. Frankfurt: Ontos Verlag.

Pettit, Philip. 1996. The Common Mind: An Essay on Psychology, Society and Politics. Oxford University Press.

- 2002. Three Aspects of Rational Explanation. In Rules, Reasons and Norms. Oxford University Press.

Smith, Michael. 2002. Exploring the Implications of the Dispositional Theory of Value. Philosophical Issues, 12, p. 329-347.

Raz, Joseph. 1975 \& 1990. Practical Reason and Norms. Princeton University Press. 1999. Engaging Reason: On the Theory of Value and Action. Oxford University Press. 